\title{
Research on Creative Design of Cultural Products Based on Seda County's Characteristic Culture
}

\author{
Fusheng Kou ${ }^{1}$, Wenming Liu ${ }^{1 *}$ \\ ${ }^{1}$ Shenyang Jianzhu University Shenyang, China
}

\begin{abstract}
This article takes Seda County's characteristic Gesar culture and folk religious culture as the research content, and conducts innovative design research on Seda County's cultural and creative products. Enumerates the cultural expression of Seda County, summarizes the design elements and design principles of cultural and creative products, and combines them with the design of fragrances to make corresponding design practice cases to provide design for contemporary cultural and creative products New innovative ideas have been introduced, and its cultural connotations and inner emotions have been conveyed.
\end{abstract}

\section{Introduction}

In recent years, my country's social and economic development has led to the further prosperity of the consumer market of all parties. The pattern of the consumer market is constantly changing, and cultural consumption has also become a special consumption pattern. It is used by various folk cultures, exhibits, museums, art galleries, while intangible cultural heritage and other individual units continue to emerge, they also arouse the individual needs of various cultural and creative products.

Although China's cultural and creative industry is in a stable development stage, many products still have not formed their own creative design style when designing. This is also a problem that my country's cultural and creative industry needs to think about when developing [1].

\section{Overview of Seda County Culture}

\subsection{Gesar Culture and Religious Culture in Seda County}

Seda County has a long history. There were traces of human life and reproduction here as early as 3000 years ago. It is one of the birthplaces of Gesar culture. Seda means "Golden Horse" in Tibetan. According to historical research, The reason for its name is a piece of horse-shaped gold unearthed in Setang territory at that time. The culture of Gesar originated from the story of King Gesar and his heroes. In his early years, King Gesar obtained the position of the throne through horse racing. Later, he won many heroic warriors through the race. , Guarding the world [2].
The local residents in Seda County are mainly nomads and monks. Every year, there are sacrificial activities of herdsmen offering sacrifices to the gods. The believers pray for the happiness of life through spiritual sustenance such as sacrifices. There are many religious buildings, including the Wuming Buddhist College, the Tower of Conquering Devil, and other religious cultures are very strong and mysterious.

\subsection{The Manifestation of the Characteristic Culture of Seda County}

Seda County has a large number of relics, legends, architecture, folk art, sculptures, stone carvings, Thangka paintings, temple dances, Tibetan operas. It is one of the rich mining areas of Gesar culture and religious culture.

- Gesar cultural heritage legend: There are many legends of Gesar cultural relics in Seda County. For example, Zhuri Mountain, where the horseshoe horn prints of King Gesar's horses and the dog paw prints of King Gesar's dogs remain on the mountain, its shape is peculiar; there are also Gesar Archery Ranges and the daily tools of the generals on Zhuri Mountain. And survival traces.

- Building: There are many buildings in Seda County. The typical Gesar Cultural Museum is shown in Figure 1. The building is composed of multiple floors. The theme color of the top floor is golden yellow, the theme color of the sixth floor is green, and the fifth floor is red. According to the different colors, they also symbolize the Golden Palace, Turquoise Palace and Coral Palace in the Gesar Palace. In order to commemorate the image of King Gesar's invincible and invincible warfare, the building is designed as a square corner. The four corners are Tieyuan Purple Palace, Yanniu Mountain Palace, East Flower Tiger Palace, Jiashan Fu Palace,

*liuwenming@sjzu.edu.cn 
which symbolizes the four brave warriors under King Sa's command, the design of Gesar Museum in Seda County follows the characteristics of the Gesar Palace, and also refers to the admiration of King Gesar.

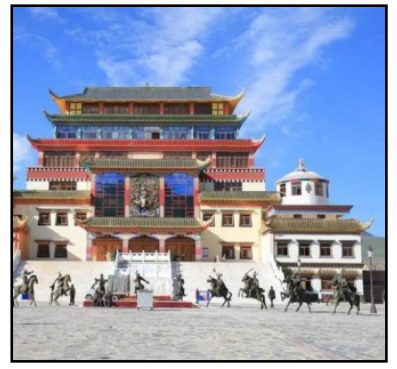

Figure 1. GGesar cultural museum of Seda County

- Prayer flags: The local residents of Seda County regard King Gesar as their ancestor and object of worship. Folk customs over the years, each household will invite monks to come to their home to recite the Gesar Blessing Sutra for three days, drink highland barley wine, light cypress branches, and mourn King Gesar in the form of burning cigarettes, and hang the King Gesar. The prayer flags with the portraits of the generals under his command are used to seek the blessing of King Gesar in the present and the future, and to find spiritual sustenance.

- Sculptures and stone carvings: There are a large number of Gesar sculptures in Seda County, which is another characteristic of Seda County. The scale of the group of painted stone carvings in Seda County is magnificent. It is mainly based on King Gesar and his generals fighting all over the world during his lifetime. The group of painted stone carvings is rich in colors, magnificent, and vividly changing the shapes of the characters.

- Thangka: Gesar Thangka paintings are widely used in families and monasteries in Seda. The style of Thangka paintings is special. They are generally drawn with gold, silver and various mineral pigments. The design and working quality are ingenious and outstanding. The Gesar culture Tangka in Seda County draws the King Gesar Swagger. The heroic image is the main content.

Gesar Tibetan Opera: The people of Seda usually hold grand mulberry simmering activities during their worship activities, and they also stage Gesar Tibetan operas, and rap artists can rap and sing Gesar stories. This is a form of lively spreading of culture.

\section{Design elements and principles of cultural and creative products}

\subsection{Design Elements of Cultural and Creative Products}

- Cultural elements: In the design of modern cultural and creative products, products are no longer limited to simple exhibits or advertisements, but an inner emotional experience of new cultural thinking. Therefore, when designing cultural and creative products, we must first consider its cultural characteristics, to meet consumers' spiritual needs for culture to the greatest extent, and to promote and guide people's aesthetic concepts and aesthetic standards to conform to the development trend of the times. Therefore, cultural and creative products The design also assumes the important task of cultural creativity and cultural promotion[3].

- Morphological elements: The design of cultural and creative products ultimately combines abstract symbols with objects and finally turns them into forms. The form of cultural and creative products is the basis for people to understand and use products, and is also a form of expression of cultural heritage.

When designing cultural and creative products, we must first determine the prototype of the product design based on people's general grasp of specific types. We should also focus on the various factors that can constitute the product, and study and analyze the entry point for consumers to resonate with culture. And the cognition of the form, combined with the development trend of contemporary culture, the design of a more saturated cultural and creative product form.

- Color element: When people are attracted by an object, it is often its unique color, and then the shape and texture of the material[4]. A good color matching design will make the entire cultural and creative product unique, improve its style and quality, and have a good impact on people's physiology and psychology.

When designing cultural and creative products, it is necessary to pay attention to the color matching of the products, and balance the overall color matching of cultural and creative products by choosing the main color. The less the number of overall colors, the more the theme can be illuminated. The main color can be determined according to the cultural nature of the product. Different regions and cultures will also have various differences, which also determine the change of the main color.

- Material elements: In addition to cultural elements, color elements and morphological elements, cultural and creative products have another important element that is material. In the design of cultural and creative products, it is also necessary to consider the rationality and safety of materials. Appropriate material selection can show its craft and cultural characteristics to a greater extent.

\subsection{Design Elements and Principles of Cultural and Creative Products}

- Cultural principle: The biggest difference between cultural and creative products and ordinary products is that they incorporate a large 
number of specific cultural elements. Therefore, cultural and creative products are important carriers of culture, which not only reflect cultural connotations, but also make cultural and creative products more unique and aesthetic value[5]. For consumers, precisely because of the need for spiritual and cultural consumption, the unique cultural and ornamental features of cultural and creative products have a high purchase value. Cultural and creative products are the carrier of culture. They carry cultural memory, and the cultural collection and purchase value of cultural and creative products will gradually burst out of its emotional significance. For cultural and creative products, once they have the unique appreciation of art and practicality of material products, they can attract consumers to a large extent to pay for the cultural value of cultural and creative products, and at the same time, the culture can be inherited.

- Practicality principle: Practicability is whether cultural and creative products have perfect functions in daily life and whether they have evaluation indicators suitable for people. This not only reflects the scientific manufacturing process of the product, but also reveals the use function and spiritual demand function of the product to a certain extent. Only the design of cultural and creative products that matches the use function of cultural and creative products with the physiological and psychological characteristics of consumers is in line with objective design laws.

- Innovation principle: For example, the innovative design of cultural and creative products is one of the important methods of cultural heritage. The point of innovation can be from the deconstruction function, use function, structural composition, appearance, color matching and other aspects of cultural and creative products, as well as design thinking. , Technology and craftsmanship.

Contemporary society is in a stage of rapid rise, and people's economic living standards are constantly improving. Therefore, people's demand for material and spiritual culture is also greatly increasing over time. Only after incorporating more innovative elements can the economic benefits of cultural and creative products be increased to promote the economic development of the entire cultural and creative industry chain and inject fresh vitality into society[6].

- Aesthetic principle: Material culture is a companion product of spiritual culture. When human beings have a certain pursuit of a certain culture, they will want to obtain the cultural form of material existence from the heart, in order to express their inner love for culture. The principle of aesthetics of cultural and creative products means that the overall beauty of the product must not only attract people's resonance with spiritual and cultural pursuits, but also follow the formal beauty rules of modern cultural and creative product design.
The critical points between the proportion and scale, unity and specificity, rhythm and rhythm, balance and symmetry, contrast and harmony, master-slave and key points of cultural and creative products are all related to the aesthetics of the product. Designing and creating excellent and beautiful cultural and creative products can not only bring good experience to users, but also bring greater benefits to local enterprises and social development.

- Economic principle: The design of cultural and creative products serves consumers. Therefore, the design has to consider the multi-directional needs of consumers. Therefore, the design concept will inevitably be affected by the economic concept. Then the economic concept is to ensure the product in the design of cultural and creative products. At the same time of quality, it is also necessary to consider the production cost and the production efficiency of cultural and creative products as much as possible.

According to the economic principles of cultural and creative product design, we can consider selecting the most cost-effective raw materials and improving process manufacturing technology in the design to increase economic benefits while ensuring that the design is "adapted to local conditions". In short, it is necessary to determine the product and consumption The positioning of the user to meet the actual needs of consumers, and the products designed through layers of careful design can maximize revenue and reduce expenditure [7].

\section{Symbolized extraction of cultural elements and innovative design of cultural and creative products in Seda County}

\subsection{Extraction and Transformation of Cultural Elements in Seda County}

Seda County is one of the birthplaces of Gesar culture. The main representative is King Gesar. In a large number of Gesar thangka paintings, the main content of the painting is warlords and war horses, and the details are depicted. They are very vivid. This plan attempts to simplify and redesign the golden horse shape to make it an element that can be used in the design of cultural and creative products, as shown in Figure 2 for the refinement of the golden horse shape. The overall form is composed of three curves, which respectively represent: Seda County (outermost profile), Gesar culture (second root), and religious culture (third root). The main meaning can be understood as the main outline of Seda County's characteristic culture. It includes Gesar culture and religious culture, and Gesar culture connects religious culture with Seda County. 


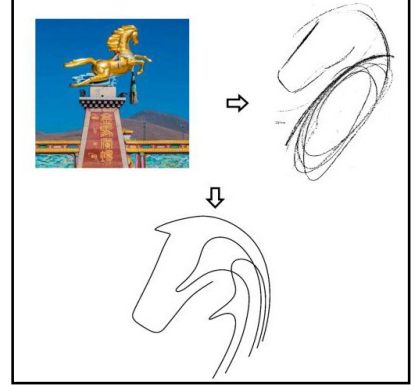

Figure 2. The refining of horse shape decoration

A large number of moire patterns can be extracted from the Thangka of King Gesar in Seda County, and after some deformation, the curling moire patterns are extracted as shown in Figure 3.

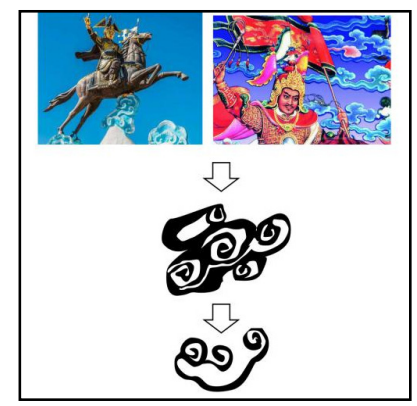

Figure 3. Refining of cirrus prints

\subsection{The Refinement of the Inner Emotional Elements of Seda County Culture}

As a material carrier, cultural and creative products carry the connotation of local culture and the pursuit of humanistic spirit, and focus on the effective combination of cultural elements and cultural and creative product design. While spreading and developing culture, they are also the inner emotional manifestation of thought and spirit.

"Expressing emotions by scenery, expressing will by objects" can be interpreted as a kind of sustenance to culture or to this area in the design and development of modern cultural and creative products. The inner emotions of the characteristic folk culture of Seda County are embodied in the respect for King Gesar and culture and the spiritual pursuit of gods, and these emotions can be combined with cultural and creative products to make them specific and serialized. Present the cultural connotation of ornamentation. In the design, modern cultural and creative product design techniques are used to refine and reorganize the external characteristics of the horse, so that the original concrete image becomes more modern and aesthetic.

\section{Design Practice of Combining Characteristic Cultural Ornamentation with Cultural and Creative Products in Seda County}

The residents of Seda County are mostly ethnic minorities (Tibetans) and spiritual monks. The two main cultures of their beliefs are Gesar culture and Buddhist culture. According to the core philosophy of Buddhism culture, which is to get rid of the sea of bitterness and cleanse the dust of the soul, after matching this Zen cultural thought with the types of cultural and creative products, the relevant design elements are analyzed in position, as shown in Table 1. It can be determined that the design theme is "Xiangdao" related cultural and creative products.

Table1. Element Alignment Analysis Table

\begin{tabular}{|c|c|c|}
\hline Element & $\begin{array}{c}\text { Counterpoint } \\
\text { Analysis }\end{array}$ & $\begin{array}{c}\text { Applicable } \\
\text { Products }\end{array}$ \\
\hline & $\begin{array}{l}\text { The horse pattern } \\
\text { element is } \\
\text { composed of three } \\
\text { curves, so the } \\
\text { trend of the curve } \\
\text { is relatively free, } \\
\text { so it can be used } \\
\text { for products that } \\
\text { are not restricted } \\
\text { by shape, can also } \\
\text { be used for } \\
\text { products with } \\
\text { restricted shape, } \\
\text { and it is also } \\
\text { suitable for } \\
\text { streamlined } \\
\text { products. }\end{array}$ & $\begin{array}{l}\text { Incense cup } \\
\text { Incense shovel } \\
\text { Incense needle } \\
\text { Incense spoon } \\
\text { Fragrant beat } \\
\text { Fragrant powder } \\
\text { box }\end{array}$ \\
\hline & $\begin{array}{l}\text { Moire is designed } \\
\text { based on a large } \\
\text { number of Gesar } \\
\text { paintings, with } \\
\text { smooth lines and } \\
\text { no loss of details, } \\
\text { suitable for small } \\
\text { products or partial } \\
\text { decoration. This } \\
\text { can make cultural } \\
\text { and creative } \\
\text { products more } \\
\text { refined }\end{array}$ & $\begin{array}{l}\text { Mica slice } \\
\text { Partial } \\
\text { connection } \\
\text { decoration of } \\
\text { incense spoon } \\
\text { and shovel } \\
\text { Surface } \\
\text { decoration } \\
\text { embellishment of } \\
\text { gray pressed and } \\
\text { incense cups }\end{array}$ \\
\hline & $\begin{array}{l}\text { The pattern of the } \\
\text { cockscomb hat is } \\
\text { based on the } \\
\text { shape of the top } \\
\text { hat worn by the } \\
\text { monks during } \\
\text { religious } \\
\text { activities. The } \\
\text { shape matches the } \\
\text { shape of the } \\
\text { shovel }\end{array}$ & Incense shovel \\
\hline
\end{tabular}




\begin{tabular}{|c|c|c|}
\hline Element & $\begin{array}{c}\text { Counterpoint } \\
\text { Analysis }\end{array}$ & $\begin{array}{c}\text { Applicable } \\
\text { Products }\end{array}$ \\
\hline & $\begin{array}{l}\text { The heart-shaped } \\
\text { Luosong pattern is } \\
\text { based on the } \\
\text { refined design of } \\
\text { the waist } \\
\text { ornaments in Seda } \\
\text { County's Tibetan } \\
\text { costumes. This } \\
\text { pattern is slender. } \\
\text { After comparison, } \\
\text { it can be analyzed } \\
\text { that it is more } \\
\text { compatible with } \\
\text { the side ash } \\
\text { pressure. }\end{array}$ & Side ash pressure \\
\hline & $\begin{array}{l}\text { The semi-circular } \\
\text { pine pattern, as } \\
\text { above, is also } \\
\text { based on the } \\
\text { refined design of } \\
\text { Tibetan costumes. } \\
\text { This shape is flat } \\
\text { and more } \\
\text { compatible with } \\
\text { the gray-pressed } \\
\text { shape }\end{array}$ & Gray pressure \\
\hline & $\begin{array}{c}\text { Tibetan } \\
\text { ornamentation }\end{array}$ & Charcoal grill \\
\hline
\end{tabular}

On this basis, through a systematic understanding of Xiangdao culture and its appliances, it was finally determined that this design combines the folk characteristic culture of Seda County with traditional Xiangdao culture. The specific design plan is follow as Figure 4 to Figure 11.

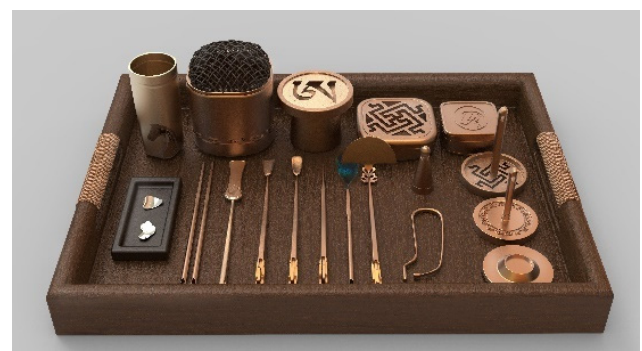

Figure 4. The display of aromatics

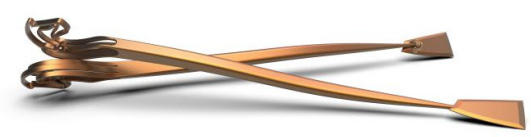

Figure 5. Incense shovel

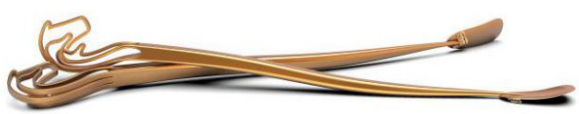

Figure 6. Incense spoon

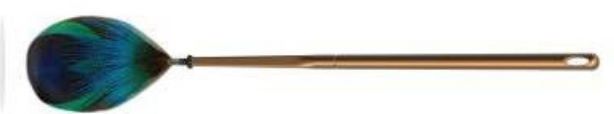

Figure 7. Incense sweep

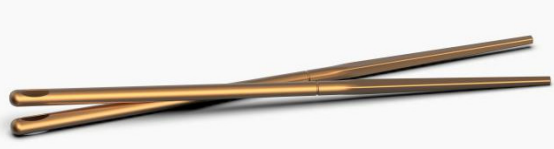

Figure 8. Incense chopsticks

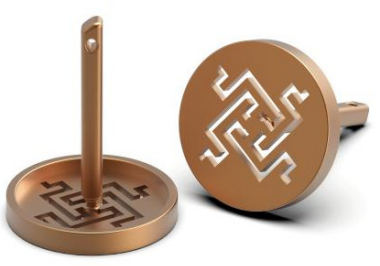

Figure 9. Incense rubbing

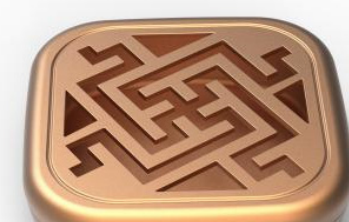

Figure 10. Fragrance of box

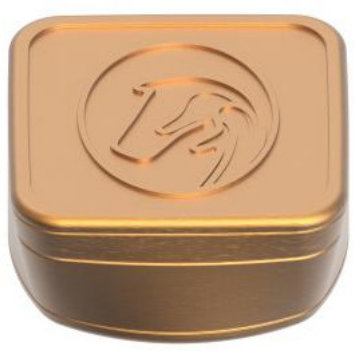

Figure 11. Incense box

The materials of the incense set in this design are brass and silver. At this stage, incense has many materials such as ceramics, stone, jade, purple sand, metal, etc. In contrast, brass materials are not afraid of heat and are full of changes in shape; Smooth surface, few bubbles; strong, low cost; easy to treat; low-key, elegant and generous color, so it is most suitable as the main material of fragrance.

Throughout the design of the whole set of incense sets, first of all, the selection of design elements also responded to the characteristic culture of Seda County and the local residents' belief in local Buddhist culture, Gesar culture and their vision for a better life. The birth was based on the background of King Gesar ascending the throne through horse racing and winning horse races. Therefore, combining it with the incense through modern design 
techniques also makes the design of this incense more modern to show Gesar culture; The basic form of an appliance is mainly based on the combination of square and circle, and the form of square and circle itself possesses a kind of philosophical reason, and the combination of square and circle has particularly clear characteristics. While the design of this set of incense sets conforms to the development trend of the times, it also shows the serialization of cultural and creative products. On this basis, consumers can feel the charm of Seda County's culture in this process, so as to achieve the purpose of coordinating cultural functions and use functions.

\section{6 conclusion}

This thesis discusses the artistic characteristics and inner emotions of Seda County's characteristic culture, and further incorporates innovative elements, so that Seda County's characteristic culture and traditional fragrance culture have been exchanged and collided, and it also promotes the living inheritance and development of culture, and summarizes the five design principles and intersection design methods of Seda County's cultural and creative product design.

The design principles are cultural principles, practical principles, innovative principles, aesthetic principles, and economic principles; on this basis, the patterns of characteristic culture are extracted and combined with traditional culture to carry out serialized cultural and creative product design. Make the use function of cultural and creative products and the function of cultural communication better unified, and create greater value.

\section{References}

1. Xing Ziyi, Wang Ting. Probe Into the Multi-path Development of Cultural and Creative Industries. Western Leather, 2020, 42(14).

2. Cao Huili, Faye Wong. On the Use and Enlightenment of the Image of Mount Fuji in the Japanese Stationery Industry. Artwork Jian, 2020.

3. Zhou Li. Research on Financial Support for the Development of Cultural and Creative Industries. Communication and Copyright, 2020.

4. Gong Wenli. Research on Yichun Folk Custom Cultural Creative Tourism Product Design from the Perspective of Cultural Industr. Daguan, 2020.

5. Hao Ninghui. Theoretical Research and Practical Discussion of Cultural and Creative Product Design. Industrial Design, 2016.

6. Yajing Hou. Research on the Application of Emotional Design in Cultural Creative Product Design. E3S Web of Conferences, 2020- 179.

7. Weiguo Zhang, Jianyao Shu, Xitong Hu, Yun Mei. Research on Product Innovation Design Methods. E3S Web of Conferences, 2020-179. 